Acta poetica 12

primavera 1991

Margarita León Vega.

\title{
El discurso de la memoria como estrategia del sujeto
}

Aquí estoy sentado sobre esta piedra aparente. Sólo mi memoria sabe lo que encierra. La veo y me recuerdo, y como el agua va al agua, así yo, melancólico, vengo a encontrarme en su imagen cubierta por el polvo, rodeada por las hierbas, encerrada en sí misma y condenada a la memoria y a su variado espejo. La veo, me veo y me transfiguro en multitud de colores y de tiempos. Estoy y estuve en muchos ojos. Yo sólo soy memoria y la memoria que de mí se tenga. (Los recuerdos del porvenir, p. 9)

El pueblo Ixtepec, donde se desarrolla el drama de Los recuerdos del porvenir, es un fantasma cercado por otros fantasmas, un acto de conciencia que se reconoce como tal, con sus limitaciones y alcances. A pesar de que su discurso está presidido por la sombra protectora de la voluntad suprema, omnisciente, de un Yo superado y distanciado de su objeto, Ixtepec es y vive en el recuerdo individual y colectivo, como un rumor de voces dispersas que intentan transformarse en discurso y dialogar. La mirada de ese yo resulta ser corta y limitada, contrastando con la incertidumbre que domina al sujeto y sus deseos de abarcarlo todo.

En esta calle hay una casa grande, de piedra, con un corredor en forma de escuadra y un jardín lleno de plantas y de polvo. Allí no corre el tiempo; el aire quedó inmóvil después de tantas lágrimas. El día que sacaron el cuerpo de la señora de Moncada, alguien que no recuerdo cerró el portón y despidió a los criados. Desde entonces las magnolias florecen sin nadie que las mire y las hierbas feroces cubren las losas del patio; hay arañas que dan largos paseos a través de los cuadros y del piano. Hace ya mu- 
cho que murieron las palmas de sombra y que ninguna voz irrumpe en las arcadas del corredor. Los murciélagos anidan en las guirnaldas doradas de los espejos, y Roma y Cartago, frente a frente, siguen cargados de frutos que se caen de maduros. Sólo olvido y silencio. Y sin embargo en la memoria hay un jardín iluminado por el sol, radiante de pájaros, poblado de carreras y de gritos. Una cocina humeante y tendida a la sombra morada de las jacarandas, una mesa en la que desayunan los criados de los Moncada. (p. 11)

La memoria de Ixtepec, esto es, el Yo estructurador del discurso, trata de construir una versión integral o esencial de la vida , y es, paradojicamente, sinecdoquica y colocada a prudente distancia. ${ }^{2}$ Así, la familia Moncada, que representa a los pobladores de Ixtepec, es trágica por excelencia, es una familia ejemplar, poseedora de un destino que se pretende "trascendente"; sus raíces y su esencia están en el pasado épico de los grandes personajes clásicos, los de La Iliada y La Odisea, los de las Sagradas Escrituras. En esa comparación implícita no sólo se puede ver el deseo de que el pasado no se diluya en el olvido, de poder resucitar y recuperar partes positivas de ese pasado que a un tiempo le restituya al Yo su status de sujeto, sino que va más allá. La memoria, es decir, la construcción del discurso, es considerada como "un acto constitutivo de la mente ligado a su propio presente y orientado hacia el futuro de su propia elaboración". 2

Desde esta altura me contemplo grande, tendido en un valle seco. Me rodean unas montañas espinosas y unas llanuras

${ }^{1}$ Hay evidentemente un distanciamiento cuando se construye una novela, dice Bajtín, pues el escritor crea un narrador o narradores, unos personajes que están ya muertos, esto es, acciones que ya han tenido lugar antes pues pertenecen al ámbito del pasado. (Bajtín, Mijail. "Dimensión temporal del héroe" Estética de la creación verbal. 117).

${ }^{2}$ En ese acto constitutivo es donde reside realmente el poder de la memoria - según Paul de Man-, por lo que el interés de reconstruir el pasado es sustituido por un interés en el futuro “...que engendra una nueva estabilidad" ( Paul de Man, en Jaques Derrida, Memorias para Paul de Man, Gedisa, Barcelona, 1989, pág. 70). 
amarillas pobladas de coyotes. Mis casas son bajas, pintadas de blanco, y sus tejados aparecen resecos por el sol o brillantes por el agua según sea el tiempo de lluvias o de secas. Hay días como hoy en los que recordarme me da pena. Quisiera no tener memoria o convertirme en el piadoso polvo para escapar a la condena de mirarme. (p. 9)

El Yo de la memoria individual y colectiva, realiza un acto de conciencia de sí mismo. Juega el juego de la nostalgia rescatando de las tinieblas del pasado prosaico, elementos para crear un nuevo tiempo y un nuevo espacio, el del mito y el de la leyenda, en los cuales el Yo es una instancia activa para que lo familiar, Io conocido, ese sustrato de afecciones y pasiones humanas primordiales, sea removido y aflore como discurso.

Así, las personas que fueron adquieren rasgos extraordinarios, se convierten en personajes, en héroes, en arquetipos: Julia Andrade, la amante del general Rosas se transforma en la Helena de Troya, en "la más querida de Ixtepec"; el fuereño Felipe Hurtado se convierte en Dionisios "el no contaminado por la desdicha"; el temible Francisco Rosas en el amante trágico, Isabel Moncada será Malinche, Antígona, Clitemnestra; los ixtepecanos un pueblo como Troya que resiste estoicamente el cerco tendido por sus enemigos.

La memoria celebra simbólicamente un rito de reconstruccion de los discursos anteriores. Rescata y reordena los materiales de los recuerdos y de la experiencia que se encontraban dispersos, en un estado caótico, amorfo. La memoria de Ixtepec realiza así un acto de fundación, de consagración del tiempo y del espacio, un acto de sacrificio necesario para dotar a los recuerdos de "alma", esto es, de significacion. El acto último de la memoria, el de su propio discurso ficcional, implica la celebración del rito, la repetición del acto cosmogónico de consagrar el espacio y de convertir al tiempo profano en tiempo mítico. ${ }^{3}$

${ }^{3}$ Dice Mircea Eliade que "Por la paradoja del rito, todo espacio consagrado coincide con el Centro del Mundo, así como el tiempo de un ritual cualquiera coincide con el tiempo mítico del "principio". Por la repetición 
El rito que celebra la memoria, ese viaje al centro de ella misma, implica un largo peregrinar por un camino sinuoso acechado por múltiples peligros. El camino es el del laberinto, está lleno de relieves y recovecos, de salidas falsas, de Minotauros. Es un rodeo por las palabras durante el ritual, durante ese primigenio acto de la creación de un mundo que se ha extinguido, que ya no existe como principio y que, tal vez, no fue como ahora desearíamos recordarlo. ${ }^{4}$

Yo supe de otros tiempos; fui fundado, sitiado, conquistado y engalanado para recibir ejércitos. supe del goce indecible de la guerra, creadora del desorden y la aventura imprevisible. Después me dejaron quieto mucho tiempo. Un día aparecieron nuevos guerreros que me robaron y me cambiaron de sitio. Porque hubo un tiempo en el que yo también estuve en un valle verde y lúminoso, fácil a la mano. Hasta que otro ejército de tambores y generales jóvenes entró para llevarme de trofeo a una montaña llena de agua, y entonces supe de cascadas y de lluvias en abundancia. Allí estuve algunos años. Cuando la Revolución agonizaba, un último ejército, envuelto en la derrota, me dejó abandonado en este lugar sediento. Muchas de mis casas fueron quemadas y sus dueños fusilados antes del incendio. (p. 9)

Así como el hombre religioso lucha por alcanzar el espacio sagrado del templo, de la montaña o de la ciudad sagrada, de la misma manera la conciencia, el Yó, ese sujeto - memoria de Ixtepec y narrador del drama-- trata de desbrozar el camino y acce-

del acto cosmogónico, el tiempo concreto, en el cual se efectúa la construcción, se proyecta en el tiempo mítico, in illo tempore en que se produjo la fundación del mundo. Así quedan aseguradas la realidad y la duración de una construcción, no sólo por la transformación del espacio profano en un espacio trascendente ("el Centro"), sino también por la transformación del tiempo concreto en tiempo mítico" ( Eliade, El mito del eterno retorno, Buenos Aires, Emecé, 1952, pág.33)

${ }^{4} \mathrm{Y}$ es que al haber una imposibilidad real de anular la distancia entre el momento del pasado y el momento del presente "...La memoria se vuelve importante como fracaso antes que como logro y adquiere un valor negativo" (Paul de Man en Derrida, 69). 
der a la zona de sí mismo como sujeto empírico, es decir, trata de acceder al ámbito de su propia experiencia humana. ${ }^{5}$

El Yo se erige en sacerdote de la palabra, en conciencia narrativa que se allega la memoria personal y colectiva, historica y mítica no sólo para quedar integrada como parte de lo humano, sino también y de algún modo, para separarse, para despegarse del mundo y contemplarse a sí mismo como sujeto trascendente, esto es, como un sujeto para quien los actos humanos - -los que realizan los sujetos empíricos- son objetos. ${ }^{6} \mathrm{Y}$ es que más allá de las vivencias concretas de un individuo o de un grupo, de la decadencia y muerte del pueblo y sus habitantes, más allá de la vigencia de algunas experiencias del pasado, el Yo memoria de Ixtepec es un sujeto que intenta estar más allá de la experiencia humana, por encima de ella, como una entidad superada.

En el discurso de esa memoria estructuradora de la ficción que es el drama del olvidado y marginal Ixtepec de Los recuerdos del porvenir, se pone de manifiesto la experiencia de los dos sujetos -el empírico y el trascendental- con mayor o menor intensidad en cada caso, pues ambos están contenidos y existen paralelamente en una misma individualidad, ${ }^{7}$ en la invidualidad que se autoproclama "yo, memoria de Ixtepec", en esa conciència, esa especie de pequeño Dios que pretende saberlo todo y juzgarlo

sEl sujeto o "yo empírico" sería el hombre, el sujeto humano, es decir, el que se encuentra y se experimenta en el mundo. El sujeto mundano, ésta "...unidad psico-física, independientemente de cómo la concibamos" (Antonio Zirión, "El sujeto trascendental en Husserl" en Crítica del Sujeto, UNAM, Col.Seminarios, 1990, pág.78)

6 "El sujeto trascendental es el sujeto para el cual todo aquel mundo, todo nuestro mundo, con todo $\mathrm{y}$ 'sus posibles mundos paralelos y con todo y todos sus sujetos empíricos, es objeto...nosotros somos sujetos trascendentales en cuanto somos sujetos para los cuales ese mundo es objeto; y en ese mundo, que es nuestro objeto, estamos incluidos nosotros mismos como sujetos empíricos" (Ibidem, pág. 80)

${ }^{7}$ Dice Antonio Zirión, parafraseando a Husserl y a Descartes que "...no vamos a ir a buscar al sujeto trascendental a otro mundo. No hay otro mundo. $\mathrm{O}$, si acaso hay otro mundo $\mathrm{u}$ otros mundos, están también en éste, aunque se trate de los infinitos mundos paralelos ... el sujeto trascendental es también el ser que somos nosotros mismos. No necesitamos ir más lejos" (79) 
todo de antemano, que se siente poseedor de un pasaporte universal por el que puede sobrevolar sin mancharse las tumbas de quienes alguna vez fueron. Es ése que -al mismo tiempo-se involucra en los deseos y en las intenciones ajenas como si fueran propias, o que intenta prestarles una lente y unas palabras a los demás por medio de las cuales se miren y se expliquen à sí mismos.

Sin el tictac, la habitación y sus ocupantes entraron en un tiempo nuevo y melancólico donde los gestos y las voces se movían en el pasado. Dorna Ana, su marido, los jóvenes y Félix se convirtieron en recuerdos de ellos mismos, sin futuro, perdidos en una luz amarilla e individual que los separaba de la realidad para volverlos sólo personajes de la memoria. Así los veo ahora, cada uno inclinado sobre su círculo de luz, atareados en el olvido, fuera de ellos mismos y de la pesadumbre que por las noches caía sobre mí cuando las casas cerraban sus persianas. (p. 19)

Ahora bien, en Los recuerdos del porvenir el yo narrador sigue el modelo de la memoria arcaica al tratar de ir al centro, lo cual significa, por otra parte, andar de nuevo, desandar el pasado y el futuro para edificar el presente -el de la memoria hecha discurso- pues según dicha memoria, todo se repite, todo retorna porque nada hay que no haya proyectado y no haya vivido el hombre anteriormente. ${ }^{8}$

Efectivamente, cuando ese yo rememora y discurre sobre los pequeños y grandes actos de quienes vivieron en Ixtepec, se ubica en un espacio donde todo tiene un significado específico, donde se transgreden las barreras temporales y espaciales para acceder a otro nivel, a otro territorio. En este caso, no se accede al Paraíso donde mora Dios, sino al Inframundo, donde una especie

${ }^{8}$ Esta idea presente en la novela de Garro, cuyo título incluso se ha atribuído a la influencia del surrealismo, parece tener raíces más antiguas, cuyas ramales traspasan las épocas y los siglos, pues "En el detalle de su comportamiento consciente, el "primitivo", el hombre arcaico, no conoce ningún acto que no haya sido planteado y vivido anteriormente por otro, otro que no era un hombre. Lo que él hace, ya se hizo. Su vida es la repetición ininterrumpida de gestas inauguradas por otros" (Eliade, 18). 
de ángeles caídos (diablos, muertos, fantasmas) vagan a través de una región desierta, inculta, nebulosa y asimilada al caos. Habitar esa zona del recuerdo, del pensamiento, significa repetir el acto primero de la creación, tomar posesión del espacio, "verbalizar$10 " .9$

Recuerdo todavía los caballos cruzando alucinados mis calles y mis plazas, y los gritos aterrados de las mujeres llevadas en vilo por los jinetes...Ya sé que todo esto es anterior al general Francisco Rosas y al hecho que me entristece ahora delante de esta piedra aparente. Y como la memoria contiene todos los tiempos y su orden es imprevisible, ahora estoy frente a la geometría de luces que inventó a esta ilusoria colina como una premonición de mi nacimiento. Un punto luminoso determina un valle. Ese instante geométrico se une al momento de esta piedra y de la superposición de espacios que forman el mundo imaginario, la memoria me devuelve intactos aquellos días y ahora Isabel está otra vez ahí, bailando con su hermano Nicolás, en el corredor iluminado por linternas anaranjadas, girando sobre sus tacones, con los rizos en desorden y una sonrisa encandilada en los labios.(p. 12)

La memoria hecha discurso, hecha escritura, resulta ser el centro o vértice en el cual es posible que confluyan pasado presente y futuro, donde pueden encontrarse personajes que pertenecen a distintas épocas. La memoria de la escritura, o dicho de otro

9 La actitud del yo narrador, "memoria de Ixtepec", emula el ritual de consagración del espacio. En esos dos primeros párafos hace conciencia de la posición que ocupa, lo que recuerda ciertas formas en las cuales los grupos humanos se establecen en los sitios que quieren ocupar como espacio sagrado. Dice Eliade al respecto, "El establecimiento de una región nueva, desconocida e inculta, equivale a un acto de creación...Una conquista territorial sólo se convierte en real después del (más exactamente, por él) ritual de toma de posesión, el cual no es sino una copia del acto primordial de la Creación del Mundo”. Aún más, “...todo territorio que se ocupa con el fín de habitarlo o de utilizarlo como "espacio vital" es previamente transformado de "caos" en "cosmos", es decir, que por efecto del ritual, se le confiere una "forma" que lo convierte en real...lo real por excelencia es lo sagrado pues sólo lo sagrado es de un modo absoluto, obra eficazmente, crea y hace durar las cosas". (Eliade, pág. 25 ) 
modo, la escritura o discurso de la memoria, puede poner de manifiesto la "realidad intacta", el "instante", pues sólo el acto poético en su automatismo y como acto de la imaginación puede acercarse a una representacion del presente, a una presencia que reivindica al memorioso de la negatividad del pasado. Esa narración de "el pasado", emula los cambios continuos de volumen, de perspectiva, cambios en cuanto a las realidades trafdas a cuento. De ahí esas zonas ciegas que deja entrever el texto, de ahí las incoherencias, el enfasis y las repeticiones.

Ese instante geométrico se une al momento de esta piedra y de la superposición de espacios que forman el mundo imaginario, la memoria me devuelve intactos aquellos días...:

Declaración de principios que explica y contiene la totalidad del discurso, el de la novela. Es manifestación explícita y abierta de su programa narrativo, de las estrategias y procedimientos discursivos que habrán de seguirse para lograr un efecto. La memoria es una especie de diamante, ("instante geométrico") cuyas facetas proyectan a un mismo tiempo imágenes múltiples, las cuales aparecen en diversos planos, con una claridad, densidad y profundidad cambiantes. Durante ese juego de espejos de la memoria activa, es posible recuperar, tener para sí, aunque sea como una ráfaga de luz, la realidad de un instante, un presente proyectado al futuro.

Como en el discurso de la memoria, en Los recuerdos del porvenir, los personajes, las situaciones y acciones, el tiempo y el lugar, las palabras, irán apareciendo como las imágenes que -manteniendo esas "huellas venideras" de las que habla Paul de Man-10 han estado tras bambalinas, latentes, y que de pronto

io "La memoria...no está esencialmente orientada hacia el pasado, hacia un presente pasado del que se juzga que existió real y previamente. La memoria permanece con huellas, con el objeto de " preservarlas", pero huellas de un pasado que nunca ha sido presente, huellas que en sí mismas nunca ocupan la forma de la presencia y siempre permanecen, por así decirlo, venideras, vienen del futuro, del porvenir. La resurrección, que es siempre el 
son "iluminadas", sacadas a la escena durante el transcurso de la narración. Como si los espejismos que se forman en el desierto de Ixtepec fueran materializándose sin perder su naturaleza imprecisa, inacabada, pues son a un tiempo huellas de una realidad que ha sido y de una realidad por cumplirse.

Ixtepec es una tumba, una estatua, que se contempla a sí misma como la Esfinge, una entidad cerrada que guarda celosamente su verdad, un espacio clausurado a la vida y al movimiento del presente. Y sin embargo, esa lápida es una especie de umbral, una vía de acceso a hechos que sucedieron y los cuales, se sabe de antemano, son imposible de conocer y de recuperar íntegramente. De ahí que resulte más viable tener acceso a lo que no se conocio, a lo que ha sido olvidado casi totalmente, pero que de algún modo sigue ahí, en los sustratos más íntimos y profundos de la experiencia humana, de la lengua. Hay que ir "cincelando", sacando de la piedra las figuras; es necesario llenar los vacíos o blancos, socavar partes; iluminar esas "zonas ocultas" de lo que quizá nunca fue Ixtepec, esa entidad muerta, borrada del mapa, de la cual sólo queda un epitafio.

A partir de la conciencia de la imposibilidad de ị al pasado es como la memoria - en tanto acto de constitución de un sujeto- se arraiga en el presente del lenguaje, de una retórica que si bien alude continuamente al pasado, se sitúa a sí misma como presencia única, como "memoria del presente":

En el esfuerzo por evocar el pasado o zambullirse en él, uno olvida el presente, dice Baudelaire, quien así quiere salvar tanto la memoria como el presente, esa memoria del presente que remite al presente a su propia presencia, es decir, a su diferencia: a la diferencia que lo vuelve único al distinguirlo del otro presente y a esa muy diferente diferencia que relaciona un presente con la presencia misma. Sólo una memoria puede reconocer este "se-

elemento formal de la" verdad", una diferencia recurrente entre un presente y su presencia, no resucita un pasado que había sido presente; compromete el futuro". (Derrida, 68-69) 
llo" diferencial, esta marca o signatura, esta patente o marca registrada que "el tiempo imprime en nuestras sensaciones"."

Es el presente 1o que en realidad le preocupa y ocupa a la novela de Elena Garro, y no el pasado como a primera vista parece. El presente que es proceso de autoconstitución del sujeto, cuyo espejo es esa escritura única, insólita, de sí mismo, como sucede con esa inefable imagen que el agua le revela, en un instante, a Narciso.

"Dice Paul de Man que quien se zambulle en el pasado, pierde la memoria del presente, "...abdica del valor y los privilegios otorgados por las circunstancias; pues casi toda nuestra originalidad viene del sello que el tiempo imprime a nuestras sensaciones" ( Derrida, pág.70) 